\title{
The use of electroencephalography in an in-patient mental handicap population
}

\author{
B.K. Puri, S. Tamrazian, G. Duffield and I. Singh
}

\begin{abstract}
The use of electroencephalography over a three year perlod in a large mental handicap hospllat was studied. There were no significant difterences in ths use according to sex or intelligence. The majortty of requests were made following selzures and in the investigation of behovioural abnormallty. In over a quarter of cases the EEG requests appeared to be incppropriate. If is suggested that a more cost-effective use would result if EECs were requested only in those cases in which the result will lead to a change in the manogement of the paitient.
\end{abstract}

The electroencephalogram (EEG) is a recording of the electrical potential activity of the brain. Although it was initially hoped that specific functional psychiatric disorders would be found to be associated with pathognomonic EEGs, this has not turned out to be the case (Kiloh et al, 1981). However, the EEG can be useful in the investigation of epllepsy, including prior to the withdrawal of antieplleptic drugs in patients with epilepsy currently in remission (Medical Research Council Antiepileptic Drug Withdrawal Study Group, 1993), and the localisation of focal lesions.

The EEG is widely used in the field of mental handicap but there are few evaluative studies of its use. In this study its current use in a large mental handicap unit is examined.

\section{The study}

Leavesden Hospital (NHS Horizon Trust) is a mental handicap hospital which serves London boroughs with a catchment population of one and a quarter million. Data from in-patients referred for EEGs over three years (1988-1991) were examined when the mean hospital population was 818. In 1988 the total hospital population was over 850 while by 1991 it was less than 800 .

Information collected from medical records included demographic data, level of mental impairment, reason for the EEG request. EEG results, and clinical consequences of the EEG findings.
In a randomly selected subgroup, the time between the EEG request being made and this investigation being carried out was also calculated.

\section{Findings}

Eighty EEGs were performed on 44 male and 36 female patients, a male to female ratio of 11:9.

There were no repeat EEGs. None of the EEGs led to further investigations rather than to a change in management. While further investigations such as CT scans did take place, these were requested at the same time as the EEG.

The average age of the patients was 42.4 years with a range of 17.8 to 83.0 years. The average age of the male patients was 39.2 years and of the female patients 46.3 years, a non-significant difference.

The intelligence quotient (IQ) was available for 57 patients and ranged from 3 to 76 , with a mean of 43.2. The correlation between 19 and age was 0.249 ( $P=0.062)$. Using ICD-10 criterta, these 57 cases were classified as borderline: $1(2 \%)$; mild: $29(51 \%)$; moderate: $13(23 \%)$; severe: $3(5 \%)$; and profound: 11 (19\%).

The reasons for requesting an EEG were : fits: 42 cases (53\%); behavioural abnormality: 32 (40\%); falls and/or collapse: 2 (3\%); confusional state: 2 (3\%); others (change in condition after ten years, development of psychotic symptomatology): 2 (3\%).

The EEG report was normal in 43 cases (54\%) and abnormal in 37 cases (46\%). The latter consisted of diffuse abnormality in 24 cases (30\%) and focal abnormality in 13 cases (16\%).

Comparing the reason for the EEG request with the results of the EEG (categorised as normal or abnormal), the null hypothesis that these two variables are independent could not be rejected $(P=0.253)$.

A change in management, for example with respect to pharmacotherapy, immediately following the reporting of the EEG, was found in 23 
cases (29\%), with no change in the remaining 57 cases (71\%).

The null hypothesis that the reason for the EEG request and change in management are independent variables was not rejected $(P=$ $0.175)$. Nor could the null hypothesis that the EEG report and change in management are independent variables be rejected $(P=0.078)$. Indeed, in 23 cases (29\%) an abnormal EEG did not lead to a change in management, while in a further nine cases (11\%) a change in management followed the report of a normal EEG. Of the former 23 cases, $17(21 \%)$ showed diffuse EEG abnormalities and six (8\%) focal abnormalities.

In a randomly chosen subgroup of 27 cases the time elapsing between the request for an EEG being made and this investigation being carried out was calculated. The time elapsing ranged from 14 to 173 days, with a mean of 44.4 days. There was no correlation between the clinical reason for the request and the delay in the EEG being performed.

\section{Comment}

There was no evidence to suggest in this inpatient population that electroencephalography was being used for the purpose of localising lesions. This would have been inappropriate as it is more useful to utilise more accurate methods of neuroimaging such as X-ray computerised tomography.

In 23 of the 80 requests for EEGs an abnormal EEG did not lead to a change in management. The most likely reason for this was that the EEG result, normal or abnormal, would not have influenced the management of the case. However, one cannot exclude the possibility that in a minority of cases a change in management should have occurred as a result of an abnormal EEG but that this did not take place. In either case, these results indicate that over a quarter of the EEG requests were inappropriate. In a further nine cases (11\%) change in management took place following a normal EEG which may imply that this did not depend on the result of the EEG. However, a normal EEG cannot be used on its own to exclude a diagnosis such as epilepsy.

It can be argued from these results that a more cost-effective way of using electroencephalography in this in-patient population would be to order it only in cases in which the result will lead to a change in the management. An additional benefit may be to reduce the long time elapsing between requesting the investigation and the EEG being carried out.

\section{References}

KnOH, L.G., McComas, A.J., OSSLETON, J.W. \& UPTON, A.R.M. (1981) Clinical Electroencephalography (4th edn). London: Butterworths.

Medical Research Councll antiepileptic DRUg WITHDRaWal STUDY GROUP (1993) Prognostic index for recurrence of seizures after remission of epilepsy. British Medical Journal, 306, 1374-1378.

B. K. Puri, Senior Registrar and Honorary Lecturer, Department of Psychiatry, Charing Cross and Westminster Medical School, St Dunstan's Road, London W6 8RP; S. Tamrazian, Registrar in Psychiatry, St Mary's Hospital Rotation, London; G. Duffield, Research Registrar in Psychiatry, Charing Cross and Westminster Rotation, London; and *I. Singh, Consultant Psychiatrist, Leavesden and Hillingdon Hospitals

*Correspondence 